\title{
Equally Performing, Unfairly Evaluated
}

\section{The social determinants of grade repetition in Italian high schools}

\author{
Guido Salza
}

University of Trento

\begin{abstract}
Grade repetition requires students with poor performance to repeat the same grade for an additional year. Despite it being commonly used, little attention has been paid to its link with inequality of educational opportunities. Based on a new large longitudinal dataset of a cohort of secondary students in Italian high schools, the present paper questions the extent to which less advantaged students (in terms of parents' educational title and migration background) are retained in grade 9 beyond pre-existing performance differences. The paper also addresses the role of school context (in terms of track and social composition) in determining a grade repetition. This paper provides evidence that, among students with comparable (poor) performance, the risk of repeating a year is substantially higher for those with parents who have less than a high school degree or have a migrant background. Additionally, grade repetition chances for students with highly educated parents are even lower in academic tracks and schools with advantaged social composition. Eventually, the paper critically assesses likely explanations for the observed gap, such as differences in parents' support and teachers' expectations.
\end{abstract}

Keywords: grade repetition; educational opportunities; teacher expectation; school failure 


\section{Introduction}

Grade repetition, which requires students with poor academic performance to repeat the same grade for an additional year, finds favor with many educators and parents. Some argue that grade repetition is an effective incentive to encourage unmotivated students to work harder (Belot and Vandenberghe 2014). Others emphasize that grade retention safeguards students who are not prepared to move to the next grade and provides additional time for knowledge strengthening and attitudinal growth (Lorence 2006; Shepard and Smith 1989). However, many critical voices claim that grade repetition generates greater disbenefits than actual benefits. While grade repetition implies a high burden for families and schools (Ikeda \& Garcia 2014; Manacorda 2008), its pedagogical efficacy is still under debate (Fertig 2004; Labaree 1984), and there is no convincing evidence of its positive impact on student achievement (Goos et al. 2021).

Another source of concern, but one that has received much less scholarly attention, is the link between grade repetition and inequality of educational opportunities. One major challenge encountered in addressing this issue is the scarcity of adequate longitudinal data. Evidence suggests that students with limited socioeconomic resources or living in disadvantaged areas are more likely to have repeated a grade in the past (OECD 2020). At least partially, this gap could have emerged from the fact that, on average, students from less advantaged backgrounds achieve lower results (Boudon 1974; Jackson 2013), which in turn raised their probability to repeat a grade. On the other hand, performance measured after grade repetition is influenced by grade repetition itself and, thus, information on pre-retention performance is necessary to disentangle the contribution of social background.

This paper analyzes the probability to repeat the first year of high school for students with different social and migratory backgrounds, net of pre-existing performance differences. The study relies on a new large longitudinal dataset of a student cohort in the Italian high school, where despite being a widespread practice, grade repetition has remained largely understudied due to the lack of adequate data.

The dataset, built for the intended purpose of this research, includes the population of students enrolled in the first year of high school (grade 9) in 2015-2016 in the three largest Northern Italian regions, adding up to over 140,000 individual students. The administrative data were collected from the National Register of Students, which follows students over time and stores all relevant information about their educational paths. These data were further combined with individual-level information from the National Institute for the Evaluation of the Educational and Training System, which administers standardized tests and background questionnaires to students. 
The richness of the data also allows to assess the moderating role of the school track and environment, a largely neglected issue in this research strand. Recent developments in the literature suggest that tracking (Carbonaro 2005; Blossfeld et al. 2016; Triventi et al. 2021), curriculum enrolment (Farkas 2011), and ability grouping (Hallinan et al. 2003) affect learning achievement. Moreover, tracking exacerbates achievement gaps for both socially disadvantaged students (Van de Werfhorst and Mijs 2010) and migrant students (Borgna 2016). Despite the significant institutional variety in timing and rules governing students' progression from one grade to another (Borodankova and Coutinho 2011; Goos et al. 2013a; Agasisti and Cordero 2017), literature has mainly focused on primary schools, and only a small portion of studies address grade repetition in secondary education (Goos et al. 2021). The case of Italy can shed light on a specific institutional setting, shared by many European countries (UIS 2012), that has until now remained understudied. In these contexts, grade repetition is virtually absent in primary school but mainly used in secondary schools.

Another relevant aspect of this institutional setting is the prominent role of teachers in the decision to retain a student, while standardized tests serve an ancillary function (Borodankova and Coutinho 2011). The high degree of teacher discretion is particularly evident in Italy, where teachers do not decide solely based on actual performance but formulate prospects of recovery based on their belief that a grade repetition would benefit a specific student. As discussed later in this paper, this offers some insight into our understanding of teachers' role in the overall persistence of educational inequality.

Taken together, the findings of this work suggest caution in the use of grade repetition policy. Among students with comparable (poor) performance, the risk of grade repetition is substantially higher for those with parents with less than high school degree or migrant background. By contrast, for students with tertiary educated parents, the risk of having to repeat a year is even lower in the academic track and in schools with a large share of advantaged students.

The remainder of this paper is organized as follows. The following section addresses major criticisms that have emerged from the academic debate on grade repetition, while section 3 depicts the link between grade repetition and the vast literature on inequalities of educational opportunities. The major features of the Italian educational system and the guidelines governing grade repetition in high school are illustrated in section 4 . The paper then describes the database and the methodology (section 5), and section 6 presents the findings. Section 7 discusses two potential mechanisms standing behind the observed gap in the likelihood of grade repetition occurrence and is finally devoted to conclusions. 


\section{Major criticisms of grade repetition}

The distribution of grade repetition among levels of education varies across educational systems, but, overall, about $11 \%$ of students have repeated at least a grade by age 15 in the EU27 countries (OECD 2020). Despite it being commonly used, grade repetition has attracted considerable criticisms. In fact, grade repetition raises direct expenses (N'tchougan-Sonou 2001) and opportunity costs (Alexander et al. 2003) for families, and imposes an additional economic burden on public education, which must cover for those students who repeat a grade (Manacorda 2008; Alexander et al. 2003). ${ }^{1}$

Critics have also argued that not only is grade repetition a costly practice, but it also lacks well-grounded pedagogical considerations. Ideally, the goal of grade repetition is twofold: to enhance the commitment of unmotivated students and their families by anticipating considerable psychological and relational costs (Fertig 2004), e.g., unhappiness produced by the separation from classmates and the stigma associated with repetition; and to allow students to recover their achievement gap before moving to the next grade (Jackson 1975). However, in practice, these two goals are often in contradiction with each other (Labaree 1983). A grade repetition to which do not correspond high costs for students is a weak motivational tool. Similarly, a grade repetition to which correspond negative anticipations is likely to undermine the future academic recovery of repeaters.

In an attempt to solve this puzzle, a considerable amount of literature has been focusing on the effects of grade repetition (Holmes and Matthews 1984; Jimerson 2001; Goos et al. 2021). Existing studies suggest that students may, in fact, benefit from grade repetition in primary school, while it seems that to repeat a year at later stages is often more harmful than not (Jacob and Legren 2004, 2009; Fruehwirth et al. 2016). However, the generalizability of these results is subject to shortcomings, as most of the studies have only been carried out in a limited number of countries (mainly the US) and in primary schools.

In Europe, grade repetition in primary school is not allowed or very rare in many countries (Borodankova and Coutinho 2011). In contexts that allow grade repetition at this early stage, the evidence is mixed (Switzerland: Bonvin et al. 2008; Flemish Belgium: Goos et al. 2013b; Germany: Fertig 2004, Kretschmann et al. 2019; France: Alet et al. 2013; and Portugal: Peixoto et al. 2016, Nunes et al. 2018). Similarly, no definitive evidence in favor of grade repetition has

\footnotetext{
${ }^{1}$ In Europe, the average yearly expenditure per student is over 9 thousand euros (OECD 2020), in turn resulting in a significant and additional burden for public budget. In Italy, upper secondary schools receive over 7,400 euros each year per student from the Ministry of Education (retrieved from www.miur.gov.it). Secondary school is virtually fees-free for families.
} 
yet been found in secondary schools. One study in Luxemburg (Klapproth et al. 2016) reports that grade repetition provided an advantage on average marks. Similarly, in France, Gary Bobo et al. (2016) finds that retained students scored higher than comparable peers on standardized test scores. One additional study from the Flanders (Lamote et al. 2014) compares similar retained and promoted students and finds that the academic self-concept of retained students increased the following year. Nonetheless, all these authors acknowledge that the advantages of retained students faded out or even turned into adverse effects in the medium and long run. By contrast, short-term negative effects have been found by Mathys et al. (2019), which observes that repetition in grade 7 and 8 resulted in a decrease in self-esteem, motivation, and perceived parental support for French-speaking Belgium students. Cockx et al. (2019) reaches similar conclusions in the Flanders, where repetition for a sample of students in grade 8 had negative effects on dropout, schooling delays, and subsequent shifts to vocational track. One study from Germany on a sample of students in grade 9 (Ehmke et al. 2010) finds null effects on math achievement and academic self-concept.

\section{Inequality in grade repetition selection}

Grade repetition decisions primarily rely on a careful evaluation of a student's academic performance and behavior in class (Jimerson 2006; OECD 2020). School rewards both cognitive and non-cognitive skills (Heckman and Kautz 2012; Bowles and Gintis 2002): cognitive (or hard) skills are necessary to process, store, and interpret information, e.g., reading, comprehension and computation (Farkas 2003); instead, non-cognitive skills are behavioral traits that, while not intrinsically intellectual or analytical in nature, are crucial to school success, e.g., motivation, effort, pro-social behavior (Rosen et al. 2010). The OECD (2020) confirms that students who had repeated a grade score, on average, 67 points lower than those who were never held back in the reading performance test. Retained students are also more likely than their classmates to skip classes and to show a milder interest in school-related goals.

However, performance and behavior are not the only factors associated with a past grade repetition. The odds of having repeated a grade significantly varies with socioeconomic status (SES) and migration background (ibidem). Past retentions are more common among low-SES students as compared to high-SES students with similar performance. Moreover, students who belong to ethnic minorities or are children of immigrants are more likely to have experienced a retention in grade. A body of country-level and case-study research suggests that students who had repeated a grade more often belong to disadvantaged socioeconomic and ethnic groups (Agasisti and Cordero 2017; Guèvremont et al. 2007; Pereira and Reis 2014; Gonzàlez-Betancor and Lòpez-Puig 2016; Meisels and Liaw 1993; Rodney et al. 1999). 
A significant limitation of these studies is that they account for performance measured after grade repetition. On average, academic performance varies between students of different social groups, and low-SES students underperform in school more often than others (Jackson 2013). The effects of social background on educational attainment via performance play a determinant role in the overall inequality of educational opportunities (Boudon 1974). Nonetheless, the level of a retained student's academic performance is, at least partially, influenced by the repetition itself.

Hence, what remains unclear is the extent to which family background plays a role in grade repetition decisions, net of prior performance. Research confirms that parents can positively affect the learning environment (Ermish et al. 2012). On average, highly educated parents are more involved in their children's educational lives (Borgonovi and Montt 2012), more often adopt concerted parenting styles (Bodovski and Farkas 2008; Lareau 2011), spend more time in childcare activities (Dotti Sani and Treas 2016), and are more likely to enroll their children in extracurricular activities (Covay and Carbonaro 2010). By contrast, low-SES students are also more dependent on prior negative outcomes, and their early disadvantages are likely to persist over time (Bernardi 2014). Recent research also confirms that family background influences evaluations and recommendations from teachers, who tend to display higher expectations for students with a privileged background (Geven et al. 2018). More in general, practices that emphasize the role of selection over performance necessarily suffer from a degree of uncertainty (Darmon 2012) and are particularly sensitive to expectations based on students' social background (Autin et al. 2018).

So far, in the European context, studies that use longitudinal data to explicitly address the role of family background have been scarce. Klapproth and Schaltz (2015) analyze grade repetition determinants for a panel of high school students in Luxembourg, and find that, compared with other low-achieving students, those with low SES and a migration background are more likely to repeat a grade. Similarly, Alet et al. (2013) finds that having highly educated parents decreases the odds of grade repetition in France primary schools. This paper contributes to this literature by exploring the extent to which, net of prior performance, family background has a residual effect on the probability to repeat a grade in Italian high schools.

\section{Grade repetition in Italy}

In Italy, education is compulsory from 6 to 16 years of age. Following five years of primary education, students enroll in the comprehensive three-year lower secondary school (grades 6 to 8). Pupils are then free to choose whether to enroll in high school or in the Vocational Education and Training sector. High school, which lasts from grade 9 to 13, offers four main tracks: 
traditional lyceum, non-traditional lyceum, technical and vocational high school. Traditional lyceum is a generalist and academic-oriented track; whereas the recently established nontraditional lyceums provide students with artistic, social science, or linguistic-focused knowledge. Technical and vocational high schools offer theoretical and practical knowledge for specific economic sectors, but the vocational track ideally prepares students for a more direct entry into the labor market. Briefly, any high school degree entitles students to enroll in tertiary education, without any difference on the chosen track.

Substantial socioeconomic inequalities characterize the Italian educational system (Jackson 2013; Contini and Triventi 2016). On average, high-SES students receive more help from parents in primary school (Raimondi et al. 2013) and display higher performance at the end of middle school (INVALSI 2019), which in turn raises their probability of enrolling to lyceums. Moreover, regardless of middle school marks, students with highly educated parents tend to enroll in academic tracks disproportionally (Panichella \& Triventi 2014; Contini \& Scagni 2013; Checchi et al. 2008). As recent research suggests (Argentin et al. 2017; Romito 2019), the ambitious educational choices of high-SES children are also more likely to find support from teachers, who conversely tend to give more conservative recommendations to low-SES students. The performance differences by social background persist during high school (INVALSI 2019).

Along with SES, another relevant source of achievement inequality is to have a migration background (Santagati 2015). On average, children of immigrants perform considerably below the national mean on standardized tests (INVALSI 2019). Additionally, teachers award them lower grades at the end of middle school (Barban and White 2011), even when compared to students with identical standardized scores (Triventi 2020). These factors may contribute to the under-representation of migrant students in academic tracks (Barban and White 2011; Azzolini et al. 2019). ${ }^{2}$

Students with an immigrant background often attend a grade lower than they would have based on their age. Aggregate 2018 statistics reports that 57\% of immigrant students in high school were enrolled in a class with younger peers, against $19.3 \%$ of native students (MIUR 2019). On the one hand, teachers often prefer to place students of recent migration in a class with younger peers to give them time to learn the language (Azzolini et al. 2019). On the other, grade repetition is significantly more common among immigrant students (ISTAT 2018a).

${ }^{2}$ While in 2018 the share of students without the Italian citizenship was around 10\% (MIUR 2019), the share of migrant students was $8.2 \%$ in technical and $12.5 \%$ in vocational high school, against $4.2 \%$ in academic tracks. 


\section{Grade repetition in Italy}

In Italy, grade repetition is almost absent in primary school and still very rare in middle school (ISTAT 2018b). The number of retained children is considerably higher in upper secondary school (Table 1). In the academic year 2016-17, 13.4\% of students in grade 9 were retained. Because traditional lyceums on average attract the highest performing students, it results in grade repetition being less frequent than in the other tracks. Indeed, vast differences across tracks exist: $6.6 \%$ of children were retained in traditional lyceum, but grade repetition share was drastically larger for other kinds of lyceums (11.8\%), technical high school (17\%), and vocational high school (21.3\%).

Tab. 1 - Share of retained students by grade and track in Italian high schools in the academic year 2016-17 (author's elaboration, public data from the Italian Ministry of Education, ISTAT 2018)

\begin{tabular}{lllll} 
Grades & 9 & 10 & 11 & 12 \\
\cline { 2 - 5 } High schools (Total) & $\mathbf{1 3 . 4 \%}$ & $\mathbf{8 . 3 \%}$ & $\mathbf{7 . 6 \%}$ & $\mathbf{5 . 5 \%}$ \\
Traditional lyceums & $6.6 \%$ & $4.4 \%$ & $4.3 \%$ & $2.5 \%$ \\
Other lyceums & $11.8 \%$ & $6.9 \%$ & $6.9 \%$ & $4.2 \%$ \\
Technical high schools & $17.0 \%$ & $10.7 \%$ & $9.9 \%$ & $7.2 \%$ \\
Vocational high schools & $21.3 \%$ & $12.7 \%$ & $10.8 \%$ & $9.2 \%$
\end{tabular}

While the share of retained students remains considerably high throughout high school, this paper analyzes the factors that determine a repetition at the end of grade 9 , when retention is the most common. Expanding on grade 9 also limits potential selection issues that may underestimate the effect of social background. In fact, in later grades, the number of students that drop out or transfer to another school grows considerably (ISTAT 2018b). Moreover, grade 9, it being the first year of high school, offers a privileged perspective on the link between grade repetition decisions and high school track choices.

According to the current national guidelines, evaluation in school is to the autonomous and competent expression of teachers. Teacher evaluation has the twofold aim of encouraging students' performance, as well as helping them to become aware of individual weaknesses and potentials. Teachers evaluate students by arranging both intermediate and year-end-of-year tests. Students receive a mark expressed on a 10-point scale on each test, with six as the passing mark. In June, teachers recommend a final mark for their subject and a conduct mark, which are approved in coordination with all class teachers. ${ }^{3}$

Teachers do not only have high discretion when assigning marks, but also in deciding over grade progression. The formal guidelines invite teachers to consider, in addition to actual

\footnotetext{
${ }^{3}$ The main legislative references that guide the evaluation of students in high school are the Decree of the President of the Italian Republic 122/2009, and the Ministerial Order 92/2007
} 
performance, the academic prospects of students. ${ }^{4}$ With this in mind, teachers must decide between full admission to the next grade, provisional admission to the next grade, or grade repetition. Provisional admission applies if teachers think that intense individual study during the summer will be enough to remedy to a disappointing school performance. The provisional admission is on condition of passing a test by the beginning of the following year; failure to do so, results in the student repeating the grade. Though, if teachers consider the chances of remedy to be poor, the student in question is directly retained in the same grade, without condition.

In practice, teachers and principals may hold different beliefs about the usefulness of retention and set school-specific standards. End-of-year grades are therefore adjusted based on the retention/promotion decision: teachers are free to (slightly) raise a student's end-of-year mark, by awarding a 6 (pass) instead of a 5 (fail), if they wish to promote him or her, despite the performance not being entirely satisfactory.

\section{Data and methodology}

The present empirical investigation relies on novel longitudinal data assembled ad hoc for this research $^{5}$. The dataset merges the information from both the National Register of Students (Anagrafe Nazionale degli Studenti - ANS), which collects student data transmitted directly by Italian schools, and the information from the National Institute for the Evaluation of the Educational System (Istituto Nazionale per la Valutazione del Sistema di Istruzione e formazione - INVALSI), an autonomous institute established in 1999 under the Ministry of Education's supervision.

ANS assigns a unique identification code to each student. By linking this information through school years, the novel dataset locates students in the educational system (school and track of attendance) and keeps records of their performance and grade progression. Although the centralization of student data was mandated by law in 2010, data transmission from schools to ANS has long remained cumbersome and has made it difficult to get records from a substantial portion of the country. As a consequence, the data release for this study refers to the entire

\footnotetext{
${ }^{4}$ In the case of underachievement in one or more subjects, the evaluation is done considering 'the possibilities that the student meets the expected formative goals by the end of the year' (Ministerial Order 92/2007)

${ }^{5}$ The data provision was possible due to a convention co-signed by the University of Turin, the Italian Ministry of Education, and the INVALSI, within a research project focusing on the determinants and the effects of grade repetition. In practice, ANS set an encryption algorithm of individual student codes to safeguard students' privacy. While the research unit did not have access to the encryption algorithm, ANS shared it with INVALSI, which could hence proceed to the data linkage.
} 
population of students enrolled in secondary schools from 2013 and 2016-17, in the three most populous northern Italian regions of Lombardy, Piedmont, and Veneto $(\mathrm{N}=140,788)$.

This paper focuses on students enrolled for the first time in grade 9 during the 2016-17 school year. For each student in this cohort, the dataset links the 2016-17 information with that of the last year of middle school (2015-16). The outcome of interest is whether a student is retained at the end of grade 9 (2016-17).

\section{Variables}

In addition to important biographical information, such as gender and year of birth, ANS includes end-of-year marks on the two main subjects (i.e., Italian and Mathematics) and behavioral conduct. The information on school performance is further enriched with a merge on individual INVALSI data. From 2007 onwards, INVALSI has started administering standardized tests in both literacy and numeracy in grades 5,8 , and 10. INVALSI also collects information on parents' educational attainment and migration background.

There are substantial gains from jointly including both teacher marks and standardized scores. On the one hand, INVALSI scores focus on a specific set of cognitive skills that are measurable and important in school (INVALSI 2019). Complementarily, end-of-year marks assigned by teachers also take into account the evaluation of crucial non-cognitive skills, such as attitudes towards teachers and classmates and autonomy in school-related tasks. On the other hand, the high discretion of teachers limits the comparison of students over end-of-year marks, while INVALSI standardized scores are equivalent across learning environments.

Ideally, the measurement of performance should be both close in time and independent from grade repetition. In practice, because teachers have the freedom to adjust their evaluation, marks that portray students just before the promotion/retention decision are endogenous. For this reason, the present analysis relies on the marks in Italian, Mathematics and behavioral conduct that teachers awarded to students at the end of grade 8 . Teacher marks in grade 8 and standardized scores were combined using Principal Component Analysis (Wold et al. 1987). The scores estimated for the first component, which explains $71 \%$ of the total variation between the variables, were then used as an index of pre-retention performance (eigenvalues and factor loadings are shown in Appendix A1).

The analysis focuses on the role of parents' highest level of education according to three categories: no more than middle school (no diploma), high school degree (diploma), and tertiary education (tertiary degree). The other main independent variable distinguishes between students born in Italy with Italian citizenship (native citizens), students born in Italy but without Italian citizenship (second-generation migrants), and students born abroad without Italian citizenship 
(first-generation migrants). At the individual level, the analysis controls for gender, and age (with a dummy for students with age above the median).

In addition to individual data, the analysis includes a range of middle school and high school contextual variables to account for performance heterogeneity and school socioeconomic composition (Table B1 in Appendix B provides school-level descriptive statistics). In particular, three variables investigate the moderation role of school context: the high school percentage of students with tertiary-educated parents, the high school percentage of students with no migration background, and the track. High schools were grouped into four main tracks, ordered from the most to the least academically-oriented track: traditional lyceums, non-traditional or 'other' lyceums, technical high schools, and vocational high schools. Table 2 provides the full list of the variables.

Tab. 2: Variables in the analysis

\begin{tabular}{|c|c|}
\hline Variables & Description \\
\hline \multicolumn{2}{|r|}{ Student level } \\
\hline Parents' highest level of education & $\begin{array}{l}\text { Highest level of education between mother and father: up } \\
\text { to middle school (no diploma), high school diploma, and } \\
\text { tertiary education (highly educated) }\end{array}$ \\
\hline Migration background & $\begin{array}{l}\text { Native citizens: born in Italy, Italian citizenship; second- } \\
\text { generation migrants born in Italy, foreign citizenship; } \\
\text { first-generation migrants: foreign-born, foreign } \\
\text { citizenship }\end{array}$ \\
\hline Gender & $1=$ female, $0=$ male \\
\hline Age & $\begin{array}{l}1=\text { whether the student is older than the modal age of the } \\
\text { classroom; } 0=\text { otherwise }\end{array}$ \\
\hline School performance index & $\begin{array}{l}\text { First component of a PCA considering Italian and } \\
\text { Mathematics end-of-year marks in grade } 8 \text {, and numeracy } \\
\text { and literacy standardized test scores from INVALSI }\end{array}$ \\
\hline Middle school average of the performance index & $\begin{array}{l}\text { The average value of the performance index in the middle } \\
\text { school in which the student was enrolled in grade } 8\end{array}$ \\
\hline $\begin{array}{l}\text { Middle school standard deviation of the } \\
\text { performance index }\end{array}$ & $\begin{array}{l}\text { The standard deviation of the performance index in the } \\
\text { middle school in which the student was enrolled in grade } \\
8\end{array}$ \\
\hline \multicolumn{2}{|r|}{ High school level } \\
\hline Track & $\begin{array}{l}\text { Traditional lyceums, other lyceums, technical high } \\
\text { schools, vocational high schools }\end{array}$ \\
\hline High school mean of school performance index & High school mean of the individual index of performance \\
\hline $\begin{array}{l}\text { High school standard deviation of school } \\
\text { performance index }\end{array}$ & $\begin{array}{l}\text { High school standard deviation of the individual index of } \\
\text { performance }\end{array}$ \\
\hline High school mean of teacher mark in behavior & $\begin{array}{l}\text { High school mean of the individual behavior mark at the } \\
\text { end of grade } 8\end{array}$ \\
\hline Social composition of the high school & $\begin{array}{l}\text { High school percentage of students with tertiary educated } \\
\text { parents }\end{array}$ \\
\hline Migrant composition of the high school & High school percentage of native students \\
\hline
\end{tabular}


Table 3 compares retained students with the overall population in the dataset. Retained students are more often male (females among retained students are $39.2 \%$ against $50 \%$ in the population) and over-age (10.9\% against $4.8 \%)$. Retained students with parents without high school degree account for almost $45 \%$ of the set, against the population mean of around $30 \%$, and few retained students have parents with tertiary degrees (13.2\% against $23.5 \%$ ). Similarly, as compared to the entire population, the share of migrants is almost twice as large. On average, retained students also achieve poorer school results.

Tab. 3 - Composition of retained students

\begin{tabular}{lrr} 
Female & $39.2 \%$ & $50.5 \%$ \\
Overage & $10.9 \%$ & $4.8 \%$ \\
Parental education & & \\
No diploma & $44.7 \%$ & $29.9 \%$ \\
Diploma & $42.1 \%$ & $46.6 \%$ \\
Higher Ed. & $13.2 \%$ & $23.5 \%$ \\
Migration status & & \\
Native citizens & $78.5 \%$ & $89.7 \%$ \\
$2^{\text {nd }}$ generation & $11.6 \%$ & $5.8 \%$ \\
$1^{\text {st }}$ generation & $9.9 \%$ & $4.6 \%$ \\
Teacher marks (grade 8) & & \\
Italian & 6.5 & 7.4 \\
Mathematics & 6.3 & 7.3 \\
Behavior & 8.2 & 8.9 \\
INVALSI scores (grade 8) & & \\
Literacy & -0.49 & 0.20 \\
Numeracy & -0.58 & 0.20 \\
Index of middle school performance & -1.54 & 0 \\
\hline
\end{tabular}

\section{Estimation}

A set of mixed-effects logistic regression with random-intercept at the school level was used to predict the contribution of parental education and immigrant background on the probability of retention in grade 9. The main advantage of random intercept models is that they acknowledge the clustered nature of data, while enabling the investigation of the group effect (Bell et al. 2019; Grilli and Rampichini 2012). Let $j=1,2, \ldots, J$ be the number of schools and $i=1,2, \ldots, N$ denote the observation for the $j$-th school. Let $y_{i j}$ be the outcome of interest, which takes 1 if the $i$-th student in the $j$-th school is retained, and 0 otherwise. Then

$$
P R\left(Y_{i j}=1 \mid x_{i j}, z_{j}\right)=\frac{\exp \left(\beta_{0}+\beta_{1} x_{i j}+\beta_{2} z_{j}+u_{j}\right)}{1+\exp \left(\beta_{0}+\beta_{1} x_{i j}+\beta_{2} z_{j}+u_{j}\right)}
$$


corresponds to the probability to be retained for the $i$-th student in the $j$-th school, where $x_{i j}$ is the vector of individual characteristics, and $z_{j}$ represents the vector of high school level variables. The parameter $u_{j}$ denotes the random variance, although the model does not directly estimate it.

The analysis was run for each track separately to produce average marginal effects (AME) for specific student profiles, which also allows to compare the effects between tracks (Mood 2010). All models control for gender, age, middle school average performance index at individual level, and track, performance and social composition at high school level.

\section{Results}

Table 4 displays the AMEs for parents' highest level of education and immigrant background. AMEs were computed for males with modal age. ${ }^{6}$ Students with high school and tertiary-educated parents are less likely to be retained in grade 9 than students with parents with a low level of education. Retained students with highly educated parents benefit from an advantage that ranges between 2.37 points (in vocational high schools) and 4.54 points (in other kinds of lyceums). A similar advantage exists for native citizens, who are less likely than migrant students to repeat grade 9. Compared to native students, the retention probabilities for migrants are between 1.75 points (in other kinds of lyceums) and 4.94 points (in the vocational track) higher.

Tab. 4 - Average Marginal Effects (percentage points)

\begin{tabular}{cccc}
$\begin{array}{c}\text { Traditional } \\
\text { lyceums }\end{array}$ & $\begin{array}{c}\text { Other } \\
\text { Lyceums }\end{array}$ & $\begin{array}{c}\text { Technical } \\
\text { high schools }\end{array}$ & $\begin{array}{c}\text { Vocational } \\
\text { high schools }\end{array}$ \\
\hline
\end{tabular}

Parental education (Ref. No diploma)

\begin{tabular}{|c|c|c|c|c|}
\hline Diploma & $-1.76^{* * *}$ & $-2.52 * * *$ & $-3.38 * * *$ & $-2.37 * * *$ \\
\hline Tertiary degree & $-3.39 * * *$ & $-4.54 * * *$ & $-5.22 * * *$ & $-2.61 * *$ \\
\hline \multicolumn{5}{|c|}{ Migration status (Ref. Native citizen) } \\
\hline $1^{\text {st }}$ generation & $2.70^{* * *}$ & $1.75+$ & $2.36^{* * *}$ & $4.94 * *$ \\
\hline $2^{\text {nd }}$ generation & $2.75^{* * *}$ & $1.42 \div$ & $3.89 * * *$ & $3.15^{* * *}$ \\
\hline No of students & 47,602 & 16,529 & 43,575 & 13,969 \\
\hline \multirow[t]{2}{*}{ No of schools } & 653 & 295 & 563 & 340 \\
\hline & & & \multicolumn{2}{|c|}{$\leftarrow p<0.10$;* $p<0.01$; *** $p<0.001$} \\
\hline
\end{tabular}

Notes: all the models controls for gender, age, performance index, mean and standard deviation of the performance index of students' middle school in 2015-16, mean and standard deviation of the behavior mark of students' middle school in 2015-16; moreover, the models account for heterogeneity at the school level by controlling for track, mean and standard deviation of the performance index, mean and standard deviation of the behavior mark, and the share of students with tertiary-educated parents and with immigrant background.

\footnotetext{
${ }^{6}$ Controlling for the performance measures, the coefficient for gender turns to non-significant
} (Table A3 in the Appendix). 
Figure 1 shows grade 9 repetition probabilities at different performance levels by track and social background. Unsurprisingly, performance distribution (right axis in the graphs) systematically differs between student profiles and high school tracks. Students with highly educated parents outperform their peers in all tracks; similarly, the performance distribution for native citizens differs from that of students with immigrant backgrounds. The comparison between tracks also shows that students in traditional lyceums are, on average, more proficient than their counterparts in the other tracks.

Overall, grade repetition probabilities increase at lower levels of performance (with zero being the average performance in the student population). While systematic differences in performance were widely expected, no deviations in the probability of being retained should be observed between student profiles, if prior performance explained the total effect of social background. Yet, the probability to get retained (plotted on the left axis) drastically diverges between student profiles at the left tail of the performance distribution. The result is that the gap between student profiles widens significantly at each point in the performance distribution below the average. To illustrate the case of traditional lyceums (first row of graphs), the gap in grade repetition probabilities between students with parents without high school diploma and students with tertiary-educated parents reaches about 10 points when approaching -2 performance points below the population mean. Roughly the same gap is observed when one turns to examine differences by migrant background: equal levels of school performance correspond to marked differences in grade repetition probabilities. The gap between student profiles is accentuated in traditional lyceums.

The picture emerges even more clearly when looking at the average advantage for parents' highest education and immigrant background. Figure 2 depicts the AMEs for parental education and migration background, separately by track. Average marginal effects were computed between the first and the $99^{\text {th }}$ percentile of the performance index (ranging from -3 to +4 points from the population mean). Consider students enrolled in traditional lyceum as an example. The advantage of having highly educated parents is already significant for students performing around the average. At this level of performance, students with tertiary-educated parents enjoy an advantage of -3 points in respect of students with parents without a high school diploma. At -2 points of the performance index, the gap dramatically reaches 18 points. By contrast, first and second-generation migrants suffer from significant disadvantages as compared with native citizen students. At -2 points of the performance index, the gap is above 10 points. 
Fig. 1: Grade repetition probabilities at different performance levels by track and social background

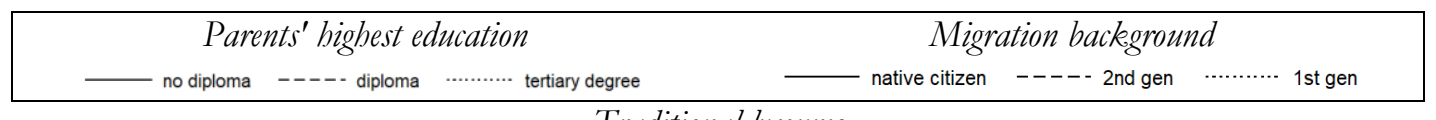
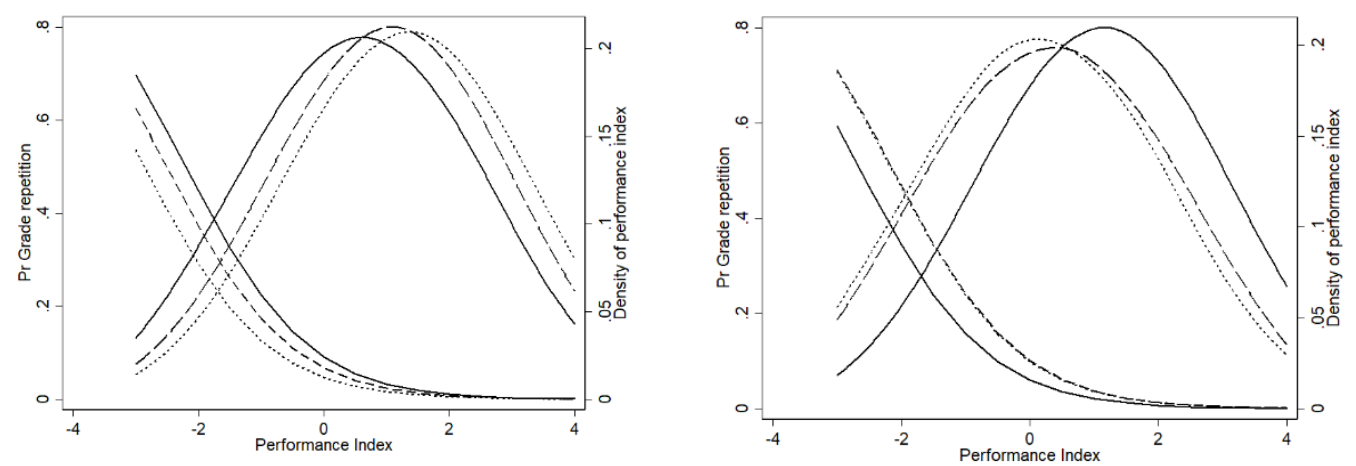

Other lyceums
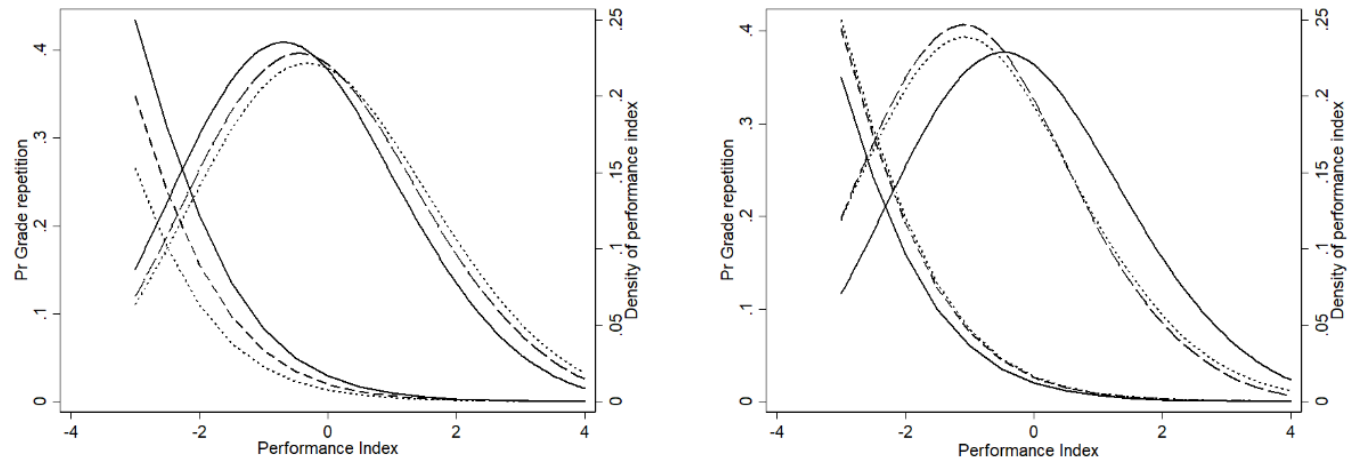

Technical high schools
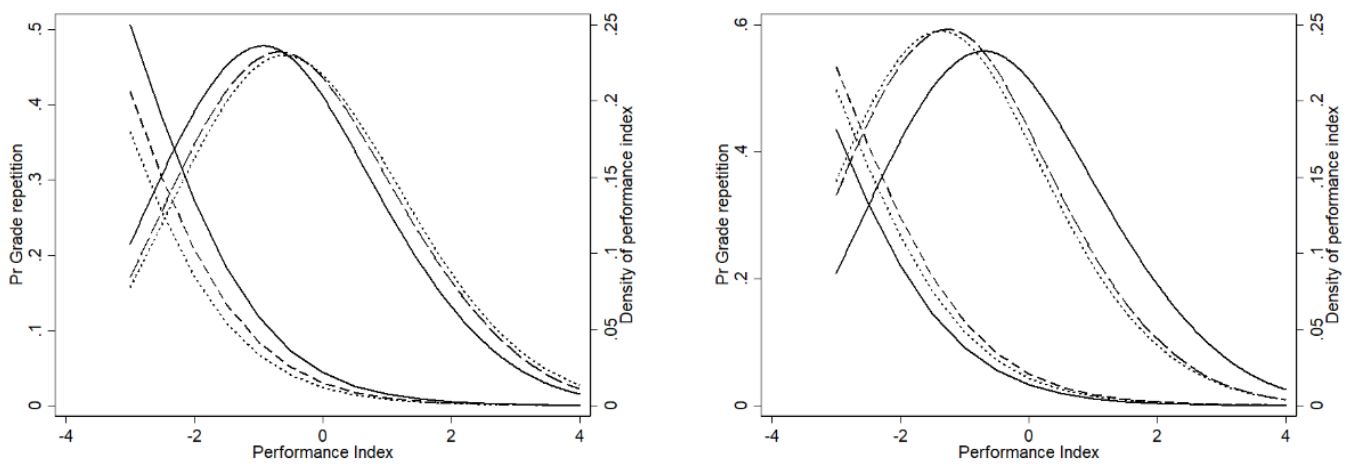

Vocational high schools
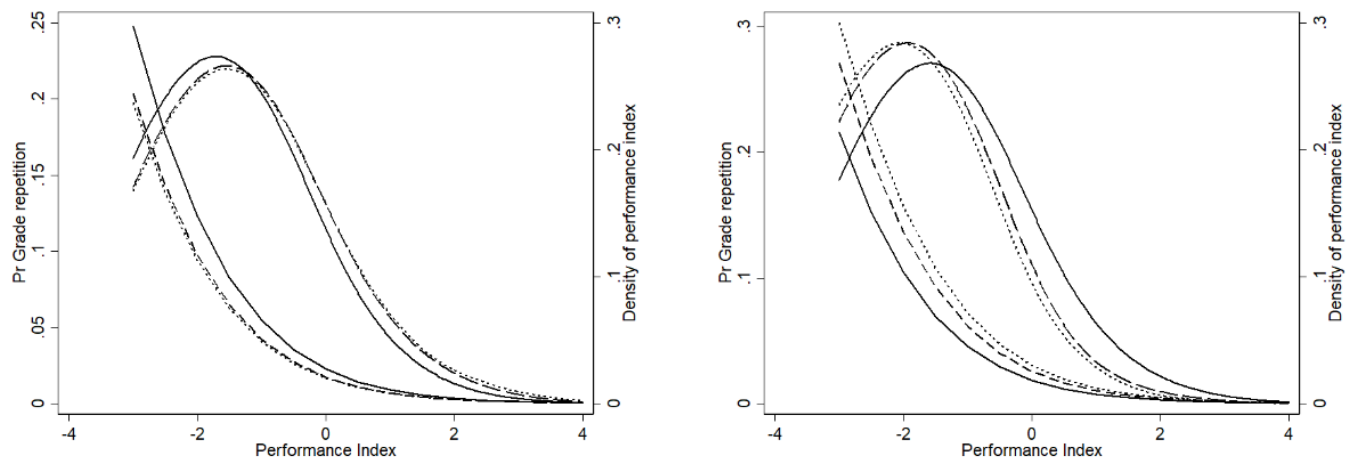

Notes: At different levels of performance ( $X$ axis, centered at population mean), density of its distribution (left y-axis), and estimated grade repetition probabilities (left y-axis) by track and student profiles. The probabilities are computed for males with modal age and enrolled in a median high school of the same track in terms of performance composition. 
Fig 2: Average Marginal Effects for parental and migration background by track

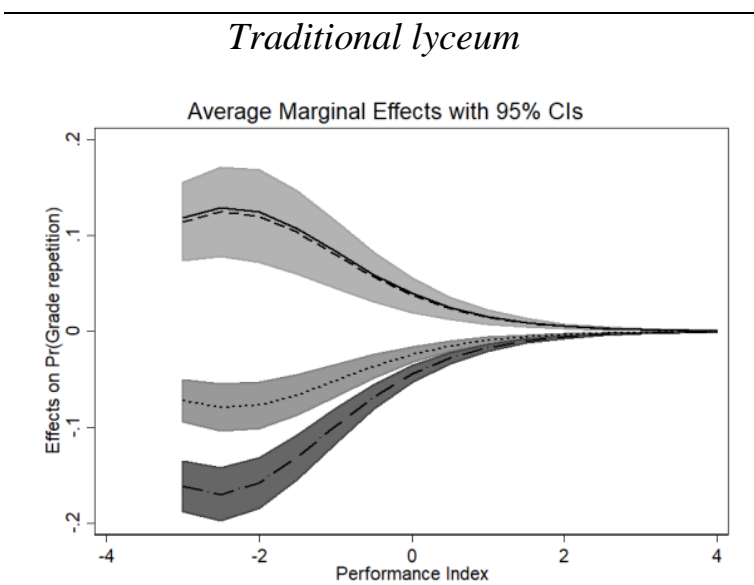

Other lyceum

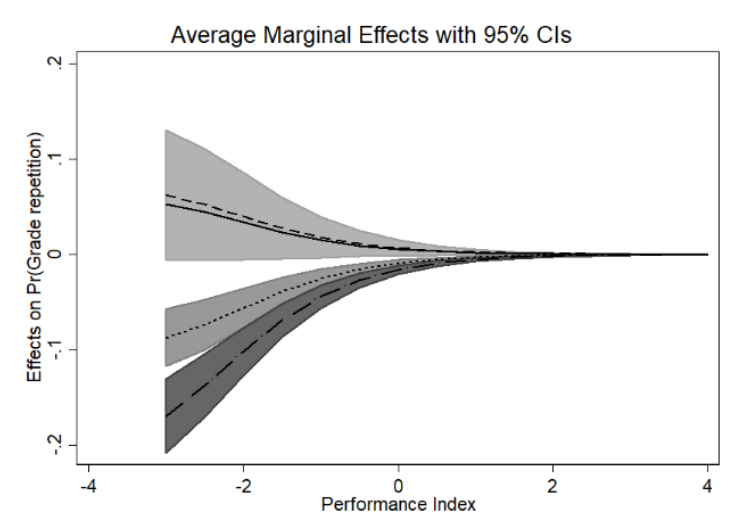

Technical high school
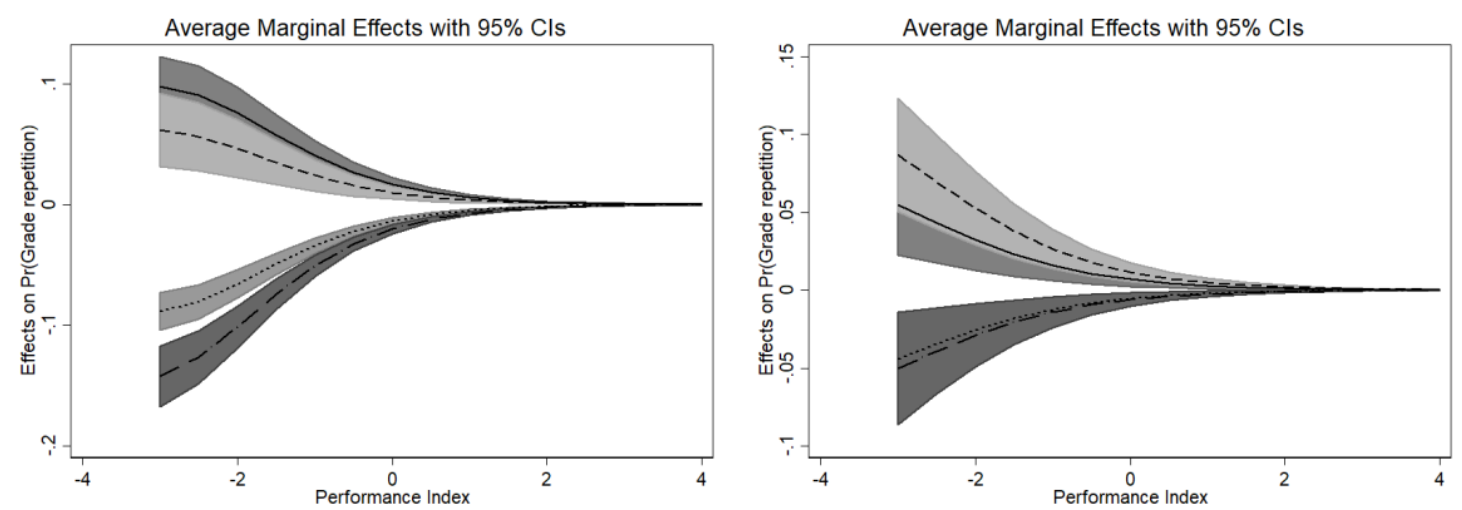

Parents with tertiary degree

Parents with high school degree

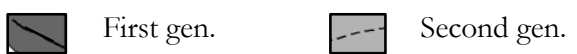

Notes: Average marginal effects for different student profiles. The probabilities are computed for males with modal age and enrolled in a median school of the same track in terms of performance and social composition. The reference categories are students with non-educated parents for highest parents' education (left column), and native students for migration background (right column), respectively. Students with high school educated parents (dotted lines) as well as tertiary educated parents (long dashed lines) have lower retention probabilities compared with children of parents without diploma. Native students are retained with less frequency than second-generation migrants (solid lines) and first-generation migrants (short, dashed lines).

In summary, prior performance held constant, students with high school-educated as well as tertiary-educated parents have significantly lower retention probabilities compared to children of parents with a low level of education. Native citizens benefit from a similar pattern, as they are retained with less frequency than second- and first-generation migrant students. 


\section{The school context}

The analysis now turns to consider the contribution of the school context to grade 9 retention probabilities. Two critical characteristics of the student body- the percentage of enrolled children with highly educated parents and the percentage of enrolled native citizens - are analyzed. Distinct random-intercept logistic regression models were run to test two cross-level interactions: the first between the individual parents' level of education and the share of students with tertiary-educated parents; the second between the individual migration background and the share of native students. The models control for the mean and standard deviation of the index performance at the school level to rule out heterogeneity in school composition in terms of performance and school standards.

Figure 3 plots the AMEs for children with high school and tertiary-educated parents by track. AMEs are shown for selected percentiles $(25,50$, and 75$)$ of the share of enrolled students with tertiary-educated parents. It shows that students with highly educated parents enjoy an additional advantage when they are enrolled to schools in higher percentiles. Compared with the other three tracks, this advantage is particularly salient for students in the traditional lyceum.

Fig. 3: Average Marginal effects at 95\% CI of parental education by tracks and percentiles in the share of enrolled students with tertiary-educated parents at the school level

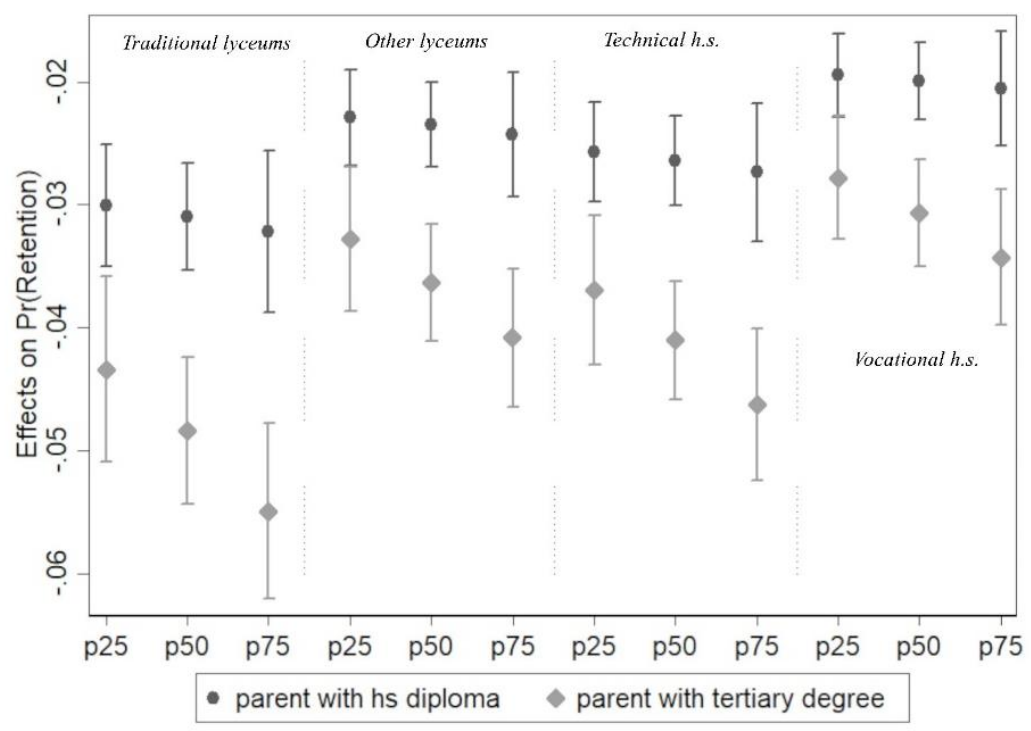

Yielding to similar conclusions, Figure 4 shows the average marginal effects in retention probabilities for first and second-generation migrants enrolled in schools with different shares of native students. In schools with very few immigrants, the risk of retention increases both for first and second-generation students. Once more, the marginal disadvantage is wider for children enrolled in traditional lyceums. 
Fig. 4: Average Marginal effects at 95\% CI of migration backgroun by tracks and percentiles in the share of enrolled native citizen students at the school level.

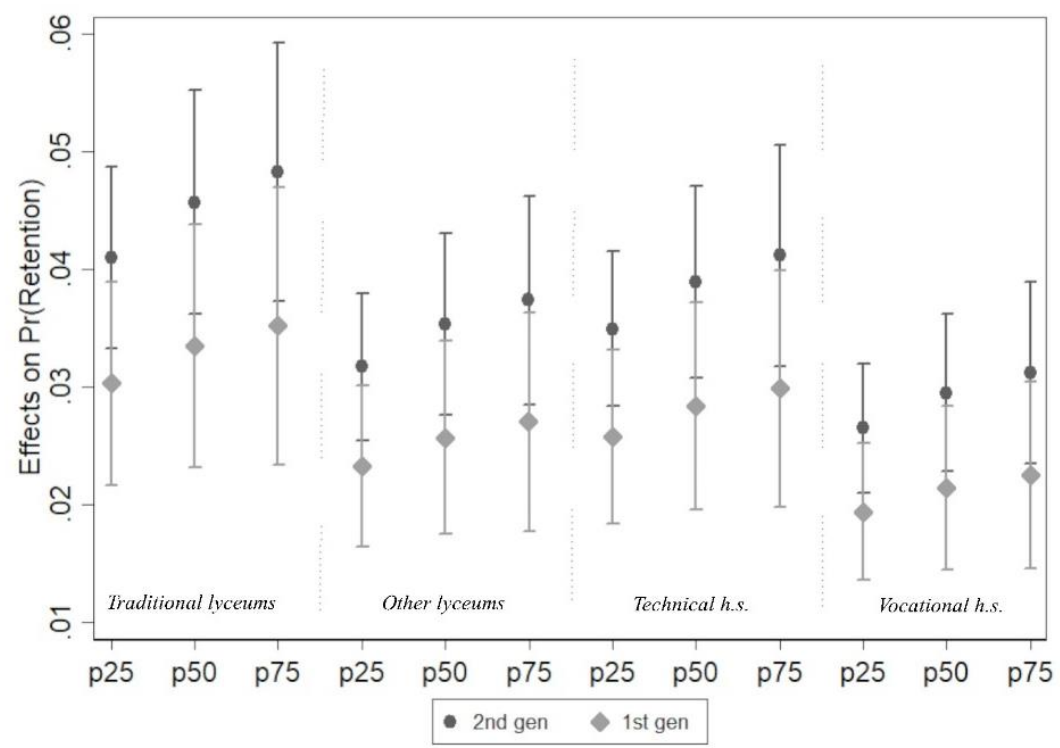

\section{Conclusions}

Disadvantaged students struggle to reach promotion more often than their peers, but preexisting differences in performance are far from fully explaining the gap in grade repetition probabilities. This paper relied on a novel longitudinal database to show that, ceteris paribus, students with parents without high school degree or immigrant background face a dramatic risk of retention in high school. Moreover, school composition exacerbates this gap, as students with a privileged background enjoy an additional advantage in traditional lyceum and schools with a selected social composition. Altogether, these results suggest more than one note of caution in the use of grade repetition.

Two hypotheses can be advanced to explain these results. Firstly, the observed gap may partly reflect inequalities in parental support that have emerged throughout grade 9. The constraints encountered by parents in supporting their children's performance - in relation to the type and number of resources they can mobilize - could explain the gap in grade repetition probability for equally (under)performing students. For instance, high-income parents, worried about an initial disappointing performance, can pay for private coaching and tutoring services, or support their children through superior cultural knowledge and skills.

Whilst differences in parental support are likely at play, the interpretation of these results should not disregard the role of teachers. Making predictions about the performance of underachieving students implies uncertainty, and teachers may include family background as an informal proxy of performance prospects. If teachers observe that, on average, prospects for students with tertiary-educated parents are more favorable than those of others, they might also 
legitimately acknowledge the role of parents when facing grade repetition decisions. For instance, teachers may presume that a child of highly educated parents will receive more (or more efficient) help at home and therefore succeed in closing the achievement gap without the need of repeating the year. This peculiar kind of statistical discrimination (Arrow 1998) does not entail stigmatization per se. Teacher evaluation can be perfectly value-free, and even accurate, it being the mere consequence of experience. Nonetheless, it implies that some salient social characteristics are employed as informal parameters in decision-making under uncertainty.

While teachers might be accurate in anticipating average performance for specific groups, making predictions also involves expectations. As growing literature attests (Van den Bergh 2010; Geven et al. 2018; Wang et al. 2018), teachers may hold biased expectations towards disadvantaged students. Teacher biases, which in the context of Italy have been detected both in awarding marks and recommending school track (Argentin \& Pavolini 2020), may also contribute to the gap in grade repetition probabilities. If teachers hold biased expectations, they will tend to discriminate against low-SES or immigrant students and, by contrast, avoid retaining students with advantaged backgrounds.

Several questions remain unanswered on the role of teachers, and researchers should not refrain from directly exploring their beliefs and motivations when they retain students. Do teachers hold rational reasons for considering grade repetition as a remedial option, or, on the contrary, do they employ it mainly as a threat and punitive device?

The mechanisms through which the school context mediates between family background and grade repetition is another important issue for future research. One unanticipated finding is that school environment exacerbates the gap between groups in grade repetition chances. There were theoretical reasons to expect that an advantaged school environment would mobilize better resources and provide social networks that could help struggling students. In practice, these findings suggest that only specific students benefit from the privileged school environment. Why do privileged schools, which may offer effective material and social resources to all underachieving students, tend to favor students with highly educated parents to a greater extent?

Other environmental factors are likely to play an important role in determining a grade repetition, and further research is needed to establish how the socioeconomic environment may interact with family resources in determining a grade repetition within a specific institutional context. On this note, a reference should be made to the limitations in terms of the external validity of this study. The gap between northern and southern Italy in terms of achievement levels and school dropouts (Ballarino et al. 2014) precludes the generalization of the results to the whole country.

Future research should eventually deepen our understanding of the effects of grade repetition in secondary schools. As the present findings attest, disadvantaged students incur in 
grade repetition disproportionally. If its effects were generally harmful, the implications would be that, despite the best of intentions, grade repetition contributes to educational inequality in its over-selection of socially disadvantaged students.

\section{Bibliography}

Agasisti, T., \& Cordero, J. M. (2017). The determinants of repetition rates in Europe: Early skills or subsequent parents' help?. Journal of Policy Modeling, 39(1), 129-146.

Alexander, K. L., Entwisle, D. R., \& Dauber, S. L. (2003). On the success of failure: A reassessment of the effects of retention in the primary school grades. Cambridge University Press.

Alet, E., Bonnal, L., \& Favard, P. (2013). Repetition: Medicine for a short-run remission. Annals of Economics and Statistics, 227-250.

Argentin, G., \& Pavolini, E. (2020). How Schools Directly Contribute to the Reproduction of Social Inequalities. Evidence of Tertiary Effects, Taken from Italian Research. Social Policies, 7(1), 149-176.

Argentin, G., Barbieri, G., \& Barone, C. (2017). Origini sociali, consiglio orientativo e iscrizione al liceo: un'analisi basata sui dati dell'Anagrafe Studenti. Social Policies, 4(1), 53-74.

Arrow, K. J. (1998). What has economics to say about racial discrimination?. Journal of economic perspectives, 12(2), 91-100.

Autin, F., Batruch, A., \& Butera, F. (2019). The function of selection of assessment leads evaluators to artificially create the social class achievement gap. Journal of Educational Psychology, 111(4), 717.

Azzolini, D., Mantovani, D., \& Santagati, M. (2019). Italy: Four Emerging Traditions in Immigrant Education Studies. In The Palgrave handbook of Race and ethnic inequalities in education (pp. 695-745). Palgrave Macmillan, Cham.

Ballarino, G., Panichella, N., \& Triventi, M. (2014). School expansion and uneven modernization. Comparing educational inequality in Northern and Southern Italy. Research in Social Stratification and Mobility, 36, 69-86.

Barban, N., \& White, M. J. (2011). Immigrants' children's transition to secondary school in Italy. International Migration Review, 45(3), 702-726.

Bell, A., Fairbrother, M., \& Jones, K. (2019). Fixed and random effects models: making an informed choice. Quality \& Quantity, 53(2), 1051-1074.

Belot, M., \& Vandenberghe, V. (2014). Evaluating the 'threat'effects of grade repetition: exploiting the 2001 reform by the French-Speaking Community of Belgium. Education Economics, 22(1), 73-89.

Bernardi, F. (2014). Compensatory advantage as a mechanism of educational inequality: A regression discontinuity based on month of birth. Sociology of Education, 87(2), 74-88.

Blossfeld, H. P., Buchholz, S., Skopek, J., \& Triventi, M. (Eds.) (2016). Models of secondary education and social inequality: An international comparison. Edward Elgar Publishing.

Bodovski, K., \& Farkas, G. (2008). "Concerted cultivation" and unequal achievement in elementary school. Social Science Research, 37(3), 903-919. 
Bonvin, P., Bless, G., \& Schuepbach, M. (2008). Grade retention: Decision-making and effects on learning as well as social and emotional development. School effectiveness and school improvement, 19(1), 1-19.

Borgna, C. (2016). Multiple paths to inequality. How institutional contexts shape the educational opportunities of second-generation immigrants in Europe. European Societies, 18(2), 180-199.

Borgonovi, F., \& Montt, G. (2012). Parental involvement in selected PISA countries and economies.

Borodankova, O., \& Coutinho, A. S. A. (2011). Grade Retention during Compulsory Education in Europe: Regulations and Statistics. Education, Audiovisual and Culture Executive Agency, European Commission. Available from EU Bookshop.

Boudon, Raymond (1974). L’inégalité des Chances. Paris: Colin.

Bowles, S., \& Gintis, H. (2002). Schooling in capitalist America revisited. Sociology of education, 118.

Carbonaro, W. (2005). Tracking, students' effort, and academic achievement. Sociology of Education, 78(1), 27-49.

Checchi, D., Fiorio, C. V., \& Leonardi, M. (2008). Intergenerational persistence in educational attainment in Italy (No. 3622). IZA Discussion Papers.

Cockx, B., Picchio, M., \& Baert, S. (2019). Modeling the effects of grade retention in high school. Journal of Applied Econometrics, 34(3), 403-424.

Contini, Dalit, and Andrea Scagni (2013). Social-origin inequalities in educational careers in Italy. In Jackson, M (Ed.) Determined to succeed? Performance versus choice in educational attainment. Stanford University Press.

Contini, Dalit, and Moris Triventi (2016). Between formal openness and stratification in secondary education: Implications for social inequalities in Italy. In Blossfeld, H. P., Buchholz, S., Skopek, J., \& Triventi, M. (Eds.). Models of secondary education and social inequality: An international comparison. Edward Elgar Publishing.

Covay, Elizabeth, and William Carbonaro (2010). After the Bell: Participation in Extracurricular Activities, Classroom Behavior, and Academic Achievement. Sociology of Education 83 (1): 2045 .

Darmon, M. (2012). Sélectionner, élire, prédire: le recrutement des classes préparatoires. Sociétés contemporaines, (2), 5-29.

Dotti Sani, G. M., \& Treas, J. (2016). Educational gradients in parents' child-care time across countries, 1965-2012. Journal of Marriage and Family, 78(4), 1083-1096.

Ehmke, T., Drechsel, B., \& Carstensen, C. H. (2010). Effects of grade retention on achievement and self-concept in science and mathematics. Studies in Educational Evaluation, 36(1-2), 27-35.

Ermisch, J., Jantti, M., \& Smeeding, T. M. (Eds.). (2012). From parents to children: The intergenerational transmission of advantage. Russell Sage Foundation.

Farkas, George (2003). Cognitive Skills and Noncognitive Traits and Behaviors in Stratification Processes. Annual Review of Sociology, 29 (1), 541-62.

(2011) Middle and high school skills, behaviors, attitudes, and curriculum enrollment, and their consequences. Whither opportunity, 71-90.

Fertig, Michael (2004). Shot across the Bow, Stigma or Selection? The Effect of Repeating a Class on Educational Attainment. 
Fruehwirth, J. C., Navarro, S., \& Takahashi, Y. (2016). How the timing of grade retention affects outcomes: Identification and estimation of time-varying treatment effects. Journal of Labor Economics, 34(4), 979-1021.

Gary-Bobo, R. J., Goussé, M., \& Robin, J. M. (2016). Grade retention and unobserved heterogeneity. Quantitative Economics, 7(3), 781-820.

Geven, S., Batruch, A., \& van de Werfhorst, H. (2018). Inequality in teacher judgements, expectations and track recommendations: A review study. Amsterdam, The Netherlands: University of Amsterdam.

González-Betancor, S. M., \& López-Puig, A. J. (2016). Grade retention in primary education is associated with quarter of birth and socioeconomic status. PloS one, 11(11), e0166431.

Goos, Mieke, Brigitte Maria Schreier, Heidi Maria Eduard Knipprath, Bieke De Fraine, Jan Van Damme, and Ulrich Trautwein. 2013(a). How Can Cross-Country Differences in the Practice of Grade Retention Be Explained? A Closer Look at National Educational Policy Factors. Comparative Education Review 57 (1): 54-84.

Goos, Mieke, Jan Van Damme, Patrick Onghena, Katja Petry, and Jerissa de Bilde (2013b). First-Grade Retention in the Flemish Educational Context: Effects on Children's Academic Growth, Psychosocial Growth, and School Career throughout Primary Education. Journal of School Psychology 51 (3): 323-47.

Goos, M., Pipa, J., \& Peixoto, F. (2021). Effectiveness of grade retention: A systematic review and meta-analysis. Educational Research Review, 34, 100401.

Grilli L. \& Rampichini C. (2012) Multilevel models for ordinal data. In: Kenett R and Salini S (eds.) Modern Analysis of Customer Surveys: with Applications using R. Ch. 19. Wiley.

Guevremont, A., Roos, N. P., \& Brownell, M. (2007). Predictors and consequences of grade retention: Examining data from Manitoba, Canada. Canadian Journal of School Psychology, 22(1), 50-67.

Hallinan, M. T., Bottoms, E., Pallas, A. M., \& Palla, A. M. (2003). Ability grouping and student learning. Brookings papers on education policy, (6), 95-140.

Heckman, J. J., \& Kautz, T. (2012). Hard evidence on soft skills. Labour economics, 19(4), 451-464.

Holmes, C. T., \& Matthews, K. M. (1984). The effects of nonpromotion on elementary and junior high school pupils: A meta-analysis. Review of educational research, 54(2), 225-236.

Ikeda, M., \& García, E. (2014). Grade repetition: A comparative study of academic and non-academic consequences. OECD Journal: Economic Studies, 2013(1), 269-315.

Invalsi (2019) Risultati Invalsi $2018 . \quad$ Retrieved from https://www.invalsi.it/invalsi/doc evidenza/2018/Rapporto prove INVALSI 2018.pdf

ISTAT (2018a) Identità e percorsi di integrazione delle seconde generazioni in Italia ISBN 978-88458-2010-6

ISTAT (2018b). Annuario statistico italiano 2018. ISBN 978-88-458-1966-7

Jackson, G. B. (1975). The research evidence on the effects of grade retention. Review of educational research, 45(4), 613-635.

Jackson, M. (Ed.). (2013). Determined to succeed?: performance versus choice in educational attainment. Stanford University Press.

Jacob, B. A., \& Lefgren, L. (2004). Remedial education and student achievement: A regressiondiscontinuity analysis. Review of economics and statistics, 86(1), 226-244. 
(2009). The effect of grade retention on high school completion. American Economic Journal: Applied Economics, 1(3), 33-58.

Jimerson, Shane R (2001). "Meta-Analysis of Grade Retention Research: Implications for Practice in the 21st Century." School Psychology Review 30 (3): 420.

Jimerson, S. R., Pletcher, S. M., Graydon, K., Schnurr, B. L., Nickerson, A. B., \& Kundert, D. K. (2006). Beyond grade retention and social promotion: Promoting the social and academic competence of students. Psychology in the Schools, 43(1), 85-97.

Klapproth, F., \& Schaltz, P. (2015). Who is retained in school, and when? Survival analysis of predictors of grade retention in Luxembourgish secondary school. European Journal of Psychology of Education, 30(1), 119-136.

Klapproth, F., Schaltz, P., Brunner, M., Keller, U., Fischbach, A., Ugen, S., \& Martin, R. (2016). Shortterm and medium-term effects of grade retention in secondary school on academic achievement and psychosocial outcome variables. Learning and Individual Differences, 50, 182-194.

Kretschmann, J., Vock, M., Lüdtke, O., Jansen, M., \& Gronostaj, A. (2019). Effects of grade retention on students' motivation: A longitudinal study over 3 years of secondary school. Journal of Educational Psychology, 111(8), 1432.

Labaree, D. (1984). Setting the standard: Alternative policies for student promotion. Harvard Educational Review, 54(1), 67-88.

Lamote, C., Pinxten, M., Van Den Noortgate, W., \& Van Damme, J. (2014). Is the cure worse than the disease? A longitudinal study on the effect of grade retention in secondary education on achievement and academic self-concept. Educational Studies, 40(5), 496-514.

Lareau, A. (2011). Unequal childhoods: Class, race, and family life, with an update a decade later. Tantor Audio.

Manacorda, M. (2008). The Cost of Grade Retention, CEP Discussion Papers 0878. Centre for Economic Performance, LSE.

Mathys, C., Véronneau, M. H., \& Lecocq, A. (2019). Grade retention at the transition to secondary school: Using propensity score matching to identify consequences on psychosocial adjustment. The Journal of Early Adolescence, 39(1), 97-133.

Meisels, S. J., \& Liaw, F.-R. (1993). Failure in Grade: Do Retained Students Catch Up? The Journal of Educational Research, 87(2), 69-77.

MIUR 2019. Gli alunni con cittadinanza non italiana A.S. 2017/2018. Retrieved from www.miur.gov.it

Nunes, L. C., Balcão Reis, A., \& Seabra, C. (2018). Is retention beneficial to low-achieving students? Evidence from Portugal. Applied Economics, 50(40), 4306-4317.

N'tchougan-Sonou, Christina H. (2001). Automatic Promotion or Large-Scale Repetition-Which Path to Quality?. International Journal of Educational Development 21 (2): 149-62

OECD (2020), PISA 2015 Results (Volume V): Effective Policies, Successful Schools, PISA, OECD Publishing, Paris

Rodney, L. W., Crafter, B., Rodney, H. E., \& Mupier, R. M. (1999). Variables Contributing to Grade Retention Among African American Adolescent Males. The Journal of Educational Research, 92(3), 185-190.

Rosen, J. A., Glennie, E. J., Dalton, B. W., Lennon, J. M., \& Bozick, R. N. (2010). Noncognitive skills in the classroom: New perspectives on educational research. RTI Press. 
Panichella, N., \& Triventi, M. (2014). Social inequalities in the choice of secondary school: Long-term trends during educational expansion and reforms in Italy. European Societies, 16(5), 666-693.

Peixoto, F., Monteiro, V., Mata, L., Sanches, C., Pipa, J., \& Almeida, L. S. (2016). "To be or not to be Retained... That's the Question!" Retention, Self-esteem, Self-concept, Achievement Goals, and Grades. Frontiers in psychology, 7, 1550.

Pereira, Manuel Coutinho, and Hugo Reis (2014). Grade retention during basic education in Portugal: determinants and impact on student achievement. Economic Bulletin and Financial Stability Report Articles, Lisbon 1.1, 61-83.

Raimondi, E., De Luca, S., \& Barone, C. (2013). Origini sociali, risorse culturali familiari e apprendimenti nelle scuole primarie: un'analisi dei dati Pirls 2006. Quaderni di Sociologia, (61), 34-49.

Romito, Marco (2019). Governing through guidance: an analysis of educational guidance practices in an Italian lower secondary school. Discourse: Studies in the Cultural Politics of Education 40.6, 773-788.

Santagati, M. (2015). Researching integration in multiethnic Italian schools. A sociological review on educational inequalities.

Shepard, Lorrie A., and Mary Lee Smith (1989). Flunking Grades: Research and Policies on Retention. Education Policy Perspectives. The Falmer Press, Taylor\&Francis, Inc.,.

Triventi, Moris (2020). Are Children of Immigrants Graded Less Generously by Their Teachers than Natives, and Why? Evidence from Student Population Data in Italy. International Migration Review, 31 .

Triventi, M., Barone, C., \& Facchini, M. (2021). Upper secondary tracks and student competencies: A selection or a causal effect? Evidence from the Italian case. Research in Social Stratification and Mobility, 76, 100626.

UIS (2012). Opportunities lost: the impact of grade repetition and early school leaving. Global Institute for Statistics Education Digest 2012 (2012).

Van den Bergh, L., Denessen, E., Hornstra, L., Voeten, M., \& Holland, R. W. (2010). The implicit prejudiced attitudes of teachers: Relations to teacher expectations and the ethnic achievement gap. American Educational Research Journal, 47(2), 497-527.

Van de Werfhorst, H. G., \& Mijs, J. J. (2010). Achievement inequality and the institutional structure of educational systems: A comparative perspective. Annual review of sociology, 36, 407-428.

Wang, S., Rubie-Davies, C. M., \& Meissel, K. (2018). A systematic review of the teacher expectation literature over the past 30 years. Educational Research and Evaluation, 24(3-5), 124-179.

Wold, S., Esbensen, K., \& Geladi, P. (1987). Principal component analysis. Chemometrics and intelligent laboratory systems, 2(1-3), 37-52. 
APPENDIX A1- School performance index computation

TAB A1-Principal components

\begin{tabular}{|lrrrr|}
\hline Component & Eigenvalue & Difference & Proportion & Cumulative \\
\hline Comp1 & 2.84294 & 2.33062 & 0.7107 & 0.7107 \\
Comp2 & 0.512318 & 0.098438 & 0.1281 & 0.8388 \\
Comp3 & 0.41388 & 0.183022 & 0.1035 & 0.9423 \\
\hline
\end{tabular}

TAB A2- Factor loadings for the school performance index (Comp1)

\begin{tabular}{|ll|}
\hline Variable & Loadings \\
\hline Teacher marks & \\
Italian & 0.5012 \\
Mathematics & 0.5097 \\
INV ALSI scores & \\
Literacy & 0.4988 \\
Numeracy & 0.4902 \\
\hline
\end{tabular}

APPENDIX A2- School level descriptive statistics

\begin{tabular}{lrrrrr} 
& $\begin{array}{r}\text { Traditional } \\
\text { lyceum }\end{array}$ & $\begin{array}{r}\text { Other } \\
\text { lyceum }\end{array}$ & Technical & Vocational & Total \\
\cline { 2 - 6 } & & & & & \\
High school means & 8.0 & 7.4 & 7.0 & 6.6 & 7.4 \\
Italian & 8.0 & 7.0 & 7.0 & 6.5 & 7.3 \\
Mathematics & 0.67 & 0.15 & -0.07 & -0.54 & 0.20 \\
Literacy score & 0.73 & -0.11 & 0.01 & -0.64 & 0.20 \\
Numeracy score & 9.2 & 9.0 & 8.6 & 8.5 & 8.9 \\
Behavior & 1.05 & -0.29 & -0.55 & -1.53 & 0.00 \\
Performance Index & 1.55 & 1.40 & 1.37 & 1.07 & 1.69 \\
(Index s.d.) & & & & & \\
$\quad$ \% of parents with & $39.5 \%$ & $22.6 \%$ & $11.7 \%$ & $7.0 \%$ & $23.5 \%$ \\
$\quad$ tertiary degree & & & & & \\
$\quad \%$ of native citizen & & & & & \\
students & $93.5 \%$ & $93.1 \%$ & $86.8 \%$ & $82.3 \%$ & $89.7 \%$ \\
\hline \hline
\end{tabular}


TAB A3- Random effects models for tracks: logits

\section{Individual level}

Female (vs male)

Over-age (vs modal age)

First generation (vs native citizens)

2nd gen (vs native citizens)

Parents' highest education (vs no degree):

High school degree

Tertiary degree

Performance index

Behavior \Conduct mark

Performance index for middle school 2015-16:

Mean

Standard dev.

$-0.31 * * *$

$-0.07$

0.21

$-0.01$

$0.21 \%$

$0.52^{* * *}$

$-0.14$

$0.52 * * *$

$0.28 t$

$-0.33 * * *$

$-0.40 * * *$

$-0.80 * * *$

$-1.15^{* * *}$

$-1.11 * * *$

$-0.81 * * *$

$0.56 * * *$

$1.01 * * *$

$0.42 *$

$0.55^{*}$

$-0.35 * *$

$1.33 * * *$

Standard dev.

\section{High school level}

Performance:

Mean of performance index

$\begin{array}{llll}0.96^{* * *} & 0.73^{* * *} & 0.94 * * * & 0.65^{* *} \\ -0.66^{* *} & -1.14^{* *} & -0.37 & -0.63^{*} \\ -0.09 & 0.19 & -0.55^{* *} & 0.42^{*} \\ 0.61 & 1.22 \% & -0.85^{*} & 0.61\end{array}$

Mean of behavioral mark

Standard dev. of behavioral mark

Social composition:

$\%$ of parents with tertiary degree

$-0.53^{*}$

$-0.86$

0.14

$-0.69$

$\%$ of native citizen students

$-3.43 * * * \quad-2.22$

Constant

1.62

$-2.22$

$-0.27$

0.34

Sigma

0.64

0.70

2.73

$-11.07 * * *$

$+p<0.10, *$ for $p<.05$, ** for $p<.01$, and *** for $p<.001$ 